\title{
Investigating the Role of the Endocannabinoid System in Early Psychosis
}

\author{
Aisling O’Neill ${ }^{1}$ and Sagnik Bhattacharyya ${ }^{1 *}$ \\ ${ }^{1}$ Department of Psychosis Studies, Institute of Psychiatry, Psychology \& Neuroscience, King's College London, London, UK
}

\begin{abstract}
Accumulating evidence suggests that dysfunction within the endocannabinoid (eCB) system may play a role in psychosis. However, little is understood about how this may be related to the neurocognitive abnormalities and symptoms of psychosis. In this paper, we summarize some of the evidence supporting the role of eCB system in psychosis, as well as the current understanding of the neurocognitive underpinnings of psychosis. We particularly focus on neuroimaging evidence pertaining to alteration in the functional integration between different brain regions in patients with psychosis, and then relate this to evidence from neuroimaging studies of the effects of cannabis and its main ingredients, such as delta-9-tetrahydrocannainol and cannabidiol. Specifically, we explore this in the context of the hypothesis that psychosis is a disorder of dysconnectivity between different brain regions, focusing particularly on three large scale functional networks (the default mode, central executive, and salience networks), alterations in which have been implicated in psychosis, and we discuss the gaps in this research thus far. Finally, we propose that an approach to investigating the role of the eCB system in psychosis may be to employ a pharmacological cannabinoid challenge paradigm to examine how experimental perturbation of the eCB system may be related to abnormalities in the brain networks implicated in psychosis. We discuss challenges associated with this approach, and suggest safe and practical options to overcome the main issues involved with such an experimental approach. Studies employing such an approach have the potential of offering insight into the neurocognitive mechanisms underlying psychosis, and identifying novel therapeutic targets.
\end{abstract}

\section{Introduction}

Psychotic disorders, such as schizophrenia, are among the top ten causes of disability worldwide, ${ }^{1}$ and are associated with a spectrum of neurocognitive deficits, which may be present from the very early stages and worsen with the onset of frank psychosis. ${ }^{2}$ Typically, the onset of psychosis occurs in late adolescence or early adulthood, ${ }^{3,4}$ with $70 \%$ of these individuals experiencing a second episode within 5-8 years. ${ }^{3,5}$ Although studies have consistently identified a number of environmental as well as genetic risk

Keywords: Psychosis; Endocannabinoid system; Connectivity; Functional neuroimaging; Cannabidiol.

Abbreviations: eCB, endocannabinoid; $\triangle 9$-THC, delta-9-tetrahydrocannabiniol; 2AG, 2-arachidonoylglycerol; CBD, cannabidiol; FC, functional connectivity; fMRI, functional magnetic resonance imaging; DMN, default mode network; SN, salience network; CEN, central executive network; rs-fMRI, resting-state functional MRI; MRC, Medical Research Council; NIHR, National Institute for Health Research; NHS, National Health Service.

Received: March 14, 2017; Revised: May 22, 2017; Accepted: May 29, 2017

*Correspondence to: Sagnik Bhattacharyya, Institute of Psychiatry, Psychology \& Neuroscience, King's College London, 16 De Crespigny Park, SE5 8AF, UK. Tel: +44 207848 0955, Fax: +44 207848 0976, E-mail: sagnik.2.bhattacharyya@kcl.ac.uk

How to cite this article: O'Neill A, Bhattacharyya S. Investigating the Role of the Endocannabinoid System in Early Psychosis. J Explor Res Pharmacol 2017;2(3):8592. doi: 10.14218/JERP.2017.00009. factors that contribute to the risk architecture of psychosis, ${ }^{4,6-8}$ mechanistic understanding as to how they may increase the risk of psychosis is unclear. Such understanding is critical to the identification of novel therapeutic targets as well as of biomarkers that may predict the risk of disease before the actual onset of illness, of relapse following onset, or indeed of biomarkers of response to treatment.

In this review, we explore the current understanding of the neurobiological underpinnings of psychosis, focusing on knowledge gained from one prominent risk factor in particular. Following this, we propose a novel approach that may help shed mechanistic insight on aspects of the presentation of psychosis. For the purposes of the present review, the risk factor of interest is cannabis use, and its activity within the related endocannabinoid system in man.

Cannabis, the endocannabinoid (eCB) system, and psychosis

Recreationally, cannabis is one of the most widely used illicit drugs in the world. ${ }^{9}$ However, its use is also recognised as one of the most preventable risk factors for the onset and relapse of psychotic disorders. ${ }^{10-13}$ A recent meta-analysis revealed that the risk of onset of psychosis amongst cannabis users is 2-4 times higher than in non-users, depending on degree of exposure. ${ }^{14} \mathrm{~A}$ separate 
meta-analytic review found that the prognosis for individuals with psychosis who continued to use cannabis following onset of illness was significantly worse compared to those who discontinued use after onset, in terms of outcomes, relapse rates, hospital admissions, and positive symptoms. ${ }^{15}$

Of particular concern has been the heavy use of high-potency strains of cannabis, especially given evidence that the availability of high-potency cannabis has been on the rise over the last two decades. ${ }^{16-18}$ In the context of cannabis use, potency is determined by the level of delta-9-tetrahydrocannabiniol $(\Delta 9-\mathrm{THC})$, the main psychoactive ingredient present in the extract of the cannabis plant. Indeed, the frequent use of high-potency strains of cannabis, which contain high levels of $\triangle 9$-THC, has been associated with significantly greater risk of onset and of relapse in psychosis, compared to use of less potent forms or to less frequent use. ${ }^{12,16,19}$

$\triangle 9-\mathrm{THC}$, the primary psychotropic constituent of cannabis, binds to the endogenous cannabinoid receptors, which are distributed throughout what is known as the "endocannabinoid system" (eCB system) ${ }^{20,21}$ The eCB system mainly constitutes endogenous cannabinoid receptors (CB1 and $\mathrm{CB} 2$ receptors) and their ligands (including anandamide, and 2-arachidonoylglycerol, or 2-AG) distributed throughout the central and peripheral nervous systems in the mammalian brain. ${ }^{22}$ Expression of the CB1 type endocannabinoid receptor is particularly high in the hippocampus, cerebellum, basal ganglia, and neocortex ${ }^{23}$ - regions involved in a number of cognitive processes of particular interest in the context of psychosis, such as learning, memory, and attention processing. ${ }^{24-26}$ Expression of the $\mathrm{CB} 2$ receptor is predominantly observed in immune cells, from where it is thought to exert an effect on immune functions. ${ }^{21} \mathrm{CB} 2$ receptor expression has also been observed in central nervous system neurons, albeit at much lower levels than the CB1 type. ${ }^{21}$ Various animal studies have proposed links between CB2 receptor function and anxiety, ${ }^{27}$ emesis, ${ }^{28}$ schizophrenia-related behaviours, ${ }^{29}$ alcohol preference, ${ }^{30}$ and impulsive behaviours. ${ }^{31}$ However, these functions - and the cellular mechanisms through which CB2 receptors exert these functions - are still disputed..$^{32}$

Consistent with the known CB1 receptor distribution, acute administration of $\triangle 9$-THC in healthy individuals has been shown to induce transient psychotic symptoms, ${ }^{33,34}$ and to cause impairments in aspects of memory and learning, ${ }^{33,35}$ abnormalities in inhibitory control processing and attentional salience processing, ${ }^{34,36,37}$ as well as alter the normal activity of the neural substrates underlying all of these processes. ${ }^{38,39}$ Evidence that modulation of these brain regions and cognitive processes by acute administration of $\triangle 9$-THC resembles aspects of the neural abnormalities and psychopathology that are also observed in schizophrenia further support a role for alterations in the $\mathrm{eCB}$ system in the pathophysiology of the disorder, and highlight it as an important target for further research. ${ }^{20}$

Independent of its role in modulating the psychoactive and psychotomimetic effects of cannabis, the eCB system has also been implicated in schizophrenia in other ways. ${ }^{40}$ One potential contributing element to the overall role of the eCB system in schizophrenia may be the relationship between eCB dysfunction and abnormal dopamine levels. ${ }^{41}$ Normal dopamine activity is involved in a number of cognitive processes, such as motivational salience, decision making, and attention and cognitive control, which are altered in schizophrenia. ${ }^{42-44}$ Striatal dopamine hyperactivity, in particular, is one of the most consistent findings in the pathophysiology of psychosis. ${ }^{45}$

Although causality is unclear, as the influence of one on the other may in fact be bidirectional, irregularities in both the availability of this neurotransmitter and in the activity of the eCB system are very likely related. This may be inferred from the dysregulated neural levels of anandamide - an endogenous cannabinoid-observed in hyperdopaminergic rat models of schizophrenia ${ }^{46}$ and increases in dopamine in the nucleus accumbens of healthy rats following acute administration of anandamide. ${ }^{47}$ Additionally, an accumulating body of evidence suggests that acute and chronic cannabis use in humans may affect dopamine release and synthesis differentially, as reviewed by Sami et al. ${ }^{48}$

eCB system alterations have also been implicated in the pathophysiology of schizophrenia through the findings of post-mortem studies, which have identified exaggerated CB1 receptor binding in the dorsolateral prefrontal cortex as well as abnormal levels of anandamide across the brain in individuals with schizophrenia. ${ }^{49,50}$ Indeed, dysregulated levels of anandamide have also been observed in animals following repeated $\triangle 9$-THC administration, ${ }^{51}$ and in the cerebrospinal fluid of first-episode psychosis patients with co-morbid high frequency cannabis use, as compared to firstepisode patients with low frequency cannabis use, and healthy controls, ${ }^{52}$ further linking alterations in components of the eCB system to the psychosis-like effects of $\triangle 9$-THC.

These findings from studies of both the effects of cannabis use on behaviour and brain activity, and abnormal eCB function in psychosis warrant a systematic investigation of the $\mathrm{eCB}$ system in the context of psychosis, and indicate that an optimal approach would be an experimental medicine paradigm, in conjunction with cannabinoid administration. However, ethical and safety considerations preclude studies involving the administration of cannabis or $\triangle 9$-THC to individuals with psychosis.

\section{Cannabidiol (CBD)}

The use of CBD, a non-psychotropic component of the cannabis plant, is a potential approach that could overcome the ethical issues surrounding pharmacological challenge studies involving administration of cannabis or $\triangle 9-\mathrm{THC}$ in patients with psychosis. There is evidence to suggest that short-term CBD administration (4 weeks) may result in an increase in peripheral anandamide levels in patients with schizophrenia, associated with a reduction in psychotic symptoms ${ }^{53}$; and may also counteract the psychotic symptoms, cognitive impairments, and associated brain activation abnormalities induced by $\triangle 9$-THC administration in healthy volunteers. ${ }^{54,55}$

Though the mechanism of action underlying the effects of $\mathrm{CBD}$ is still unclear, a range of molecular mechanisms have been suggested as acting either individually or in conjunction with others to produce the aforementioned notable effects. ${ }^{53,56}$ One theory relates to the potential action of $\mathrm{CBD}$ as a high-potency antagonist of $\mathrm{CB} 1$ receptor agonists, ${ }^{57}$ which - in opposition to the partial agonist activity of $\triangle 9-\mathrm{THC}$ at $\mathrm{CB} 1$ receptors - may result in the contrasting effects induced by the two exogenous cannabinoids. Another prominent argument concerns the ability of CBD to enhance anandamide signalling via the inhibition of anandamide uptake and intracellular degradation. ${ }^{56,58}$ As noted earlier, this increase in anandamide levels has been associated with decreases in psychotic symptoms, and though the exact nature of this relationship remains inconclusive, it is likely that this ability to increase anandamide signalling is related to the antipsychotic properties of CBD. ${ }^{53}$

Nonetheless, consistent with this evidence overall, in recent years there has been considerable interest in a potential role for $\mathrm{CBD}$ as an antipsychotic treatment. ${ }^{59}$ Additionally, CBD has also been found to display neuroprotective properties, and has demonstrated a low side effect profile, and tolerability in doses of up to $1,500 \mathrm{mg} \cdot{ }^{60,61}$ All of these factors combine to make CBD an ideal tool for the safe perturbation of the eCB system in a pharmacologi- 
cal challenge paradigm, and will allow the further investigation of abnormalities of the eCB system in clinical populations.

\section{Psychosis as a disorder of dysconnectivity}

Although abnormal patterns of brain activity in specific brain regions are well documented in psychosis and have been associated with aspects of the illness, ${ }^{62}$ these localised abnormalities have thus far failed to provide a comprehensive account of the neurocognitive mechanisms underlying the multiple, complex phenotypic features of the disorder. ${ }^{63,64}$ There is increasing recognition that attributing even very specific symptoms, such as auditory hallucinations, to dysfunction in just one localised area of the brain is overly simplistic, and that such an approach is far less plausible for the broad range of positive and negative psychotic symptoms and ubiquitous cognitive deficits that characterize psychotic disorders, such as schizophrenia. ${ }^{64}$

This is further complicated by the fact that these symptoms are not only heterogeneous in their presentation across individuals with psychosis, but can also change in prominence across time within the same individual. This limitation has prompted a more integrated approach, focusing instead on the interaction over time of brain regions that have been traditionally functionally segregated. The ensuing research drove the development of what is known as the dysconnectivity theory of schizophrenia, ${ }^{65}$ which describes the psychopathology of the disorder as resulting from an underlying dysconnection syndrome. ${ }^{65-67}$ The term functional connectivity (FC) describes the temporal relationship between activation measured in different brain regions, either at rest or during a task, ${ }^{68}$ and is inferred from the correlation between regional fluctuations in the blood-oxygen-level-dependent signal of different brain regions, measured using functional magnetic resonance imaging (fMRI).

A number of studies have investigated FC alterations in the context of psychosis, which are summarized below.

\section{Results of resting state studies}

A popular approach in neuroimaging literature has been to describe brain regions as being organized into functional neural networks, three of which are of particular interest in the context of FC research across neuropsychiatric diagnoses. ${ }^{64}$ These networks are the Default Mode Network (DMN), the Salience Network (SN), and the Central Executive Network (CEN). Resting-state functional MRI (rs-fMRI) techniques have proven particularly useful in the study of such networks in psychosis. They provide a means of representing intrinsic brain function and connectivity between brain regions under resting as opposed to activation conditions, which involve external stimuli or induced reactions. ${ }^{69,70}$

The DMN is largely active at rest, and as such, is engaged by a range of internally directed thought processes, including self-referential thought, aspects of autobiographical memory, and future simulations - all processes that are notably disrupted in schizophrenia. ${ }^{71}$ Anatomically, the core nodes of the DMN include the posterior cingulate cortex and the precuneus, the medial prefrontal cortex, and the angular gyrus. ${ }^{72}$ Additional regions involved in DMN processes include the dorsal medial subsystem, and the medial temporal subsystem. ${ }^{72}$

Normally, DMN and CEN activity are thought to be anti-correlated. ${ }^{73}$ That is, DMN activity is reduced during externally oriented task states, at the same time as CEN activity is increased, and vice versa for the internally oriented/resting state. As such, the CEN is thought to be responsible for higher level cognitive functions (e.g. attentional control, and executive task performance), and is rooted in the dorsolateral prefrontal cortex and the posterior parietal cortices. ${ }^{74}$

Critical to the appropriate engagement and disengagement of CEN and DMN activity, the SN is believed to moderate this "switching" between networks through the attribution of salience to external or internal stimuli. ${ }^{64}$ In salience literature, the attribution of salience refers to the assignment of importance to external stimuli or internal mental events, critical in the processing of an individual's experiences. ${ }^{75}$ The anterior insula (a core region in the $\mathrm{SN}$ ) is thought to moderate the shift between activity in the DMN (internally directed processes) and CEN (externally directed processes) by increasing cognitive and task control system activity, whilst suppressing DMN activity when a salient event is detected. ${ }^{75,76}$ In contrast, in individuals with schizophrenia, abnormal levels of dopamine in the $\mathrm{SN}$ are thought to result in aberrant anterior insula activity (with a particularly high expression of dopamine D1 receptors in the anterior insula), which in turn results in the misattribution of salience to external/internal stimuli, and consequently the dysfunctional switching between DMN and CEN engagement. ${ }^{64,77-79}$

The functional consequences of this sequence include greater connectivity between the DMN and CEN, greater connectivity within the DMN, and decreased anterior insula activity occurring at rest, as well as a failure to suppress DMN activity during externally driven tasks. ${ }^{77,80}$ Decreased FC between the SN and both the DMN and CEN at rest has also been reported in patients with schizophrenia, ${ }^{77,81}$ as well as an overall reduction in the strength of negative FC between task-positive and task-negative networks during both rest and task in patients diagnosed with schizophrenia, as well as with other psychotic disorders. ${ }^{73,80}$

It is thought that the potential symptomatic consequences of these connectivity abnormalities range from hallucinations and deficits in emotional processing (resulting in part from misattribution of salience) to deficits in self-referential thinking (resulting in part from the over-engagement of the DMN). As such, this triple network model is thought to provide the most unified account to date of the mechanisms underlying the spectrum of different psychosis symptom domains - from deficits of self to the classic positive, negative and cognitive domains. ${ }^{82}$

Apart from the anterior insula, an additional core node of the $\mathrm{SN}$ is the dorsal anterior cingulate cortex, though its broader functions also rely on input from the amygdala, ventral striatum, and the substantia nigra/ventral tegmental area $^{75}$ - with a high expression of both dopamine and $\mathrm{CB} 1$ receptors observed in the dorsal and ventral striatum, and in the substantia nigra. ${ }^{21,83}$

If eCB dysfunction were to have a role in the pathophysiology of psychosis, one would expect it to modulate components of the three networks described here, in a manner consistent with alterations observed in those with psychosis. However, this has yet to be examined. Indeed, few studies have investigated the effects of $\Delta 9$ THC on FC during cognitive tasks or at rest. The limited available evidence suggests that $\triangle 9-\mathrm{THC}$ can induce a reduction in connectivity between the $\mathrm{SN}$ and the $\mathrm{CEN}$, increase connectivity between the DMN and CEN, and increase connectivity within the DMN, during salience processing in healthy individuals ${ }^{37,84}$ —reflective of those disturbances described in the triple network model. This, coupled with the high distribution of CB1 receptors within the SN and the propensity for acute $\triangle 9$-THC to impair performance on salience processing tasks in healthy individuals,${ }^{85}$ would suggest a plausible if as yet undefined role for eCB dysfunction in the triple network model of schizophrenia. 


\section{Results of cognitive activation studies}

In the context of characterising overall functional dysconnectivity in schizophrenia, studies that employ cognitive tasks are essential for a more complete understanding of the nature of disturbances observed during psychosis. Learning and memory impairments are particularly well-documented phenomena in the neurocognitive profile of individuals with schizophrenia, both in the context of comorbid cannabis use and its absence, ${ }^{86,87}$ and are similarly observed in healthy individuals following both acute $\triangle 9$-THC administration and chronic cannabis use. ${ }^{39,88}$ Across all illness stages of schizophrenia, but particularly during the first episode of psychosis, memory tasks involving verbal learning and encoding have been found to display significant impairments, compared to healthy individuals. ${ }^{26}$ Similarly, verbal learning, memory, and attention appear to be the most consistently impaired cognitive domains in studies of acute and chronic cannabis use. ${ }^{89}$

Encoding refers to the mental storage of information for later retrieval or recollection from short-term or long-term memory, and is crucial for learning. ${ }^{86}$ The brain regions largely involved in verbal learning and encoding include, but are not limited to, the medial temporal lobe (formation of new memories) and the prefrontal cortex (essential for executive control functions and salience processing). ${ }^{90-92}$ Both regions display significant abnormalities in activation and connectivity during encoding and recall across illness stages in schizophrenia. ${ }^{86,}$ 91-96 Specifically, reports of connectivity-related abnormalities have included decreases in FC between the DMN and some regions involved in executive control, and decreased connectivity within the DMN during encoding and recall tasks. ${ }^{94-96}$ Connectivity within the DMN and the regions involved in executive control was found to correlate positively with task performance, ${ }^{93}$ indicating a failure to recruit crucial neural resources that is linked to level of cognitive impairment.

Neural abnormalities in corresponding regions have been observed during encoding and recall tasks in healthy individuals administered $\triangle 9$-THC, including decreases in insular activity during encoding, ${ }^{97}$ increases in parahippocampal activity while learning during repeated trials of encoding, and a change in ventrostriatal activation during repeated trials of cued word recall condition. ${ }^{98}$ While the effect of $\triangle 9$-THC on the FC between these regions during encoding and recall has not previously been explored, these studies do highlight the importance of such investigations, and of further research of the eCB system overall.

Effect of eCB system perturbation on neurocognitive substrates implicated in psychosis

As outlined earlier, while the justification for investigating the role of eCB dysfunction in psychosis is clearly there-focusing particularly on the relationship between experimentally induced perturbations of the eCB system and the function of neural substrates implicated in psychosis, as well as symptoms and cognitive changes characteristic of psychosis - this has yet to be carried out systematically. Additionally, as discussed previously, though its safety and pharmacological profile make CBD an ideal tool for safe perturbation of the eCB system in clinical populations, to our knowledge, no study as yet has investigated the effects of such perturbation on the neurocognitive substrates implicated in psychosis, in psychosis patients directly. However, given the clear parallels between neurocognitive abnormalities observed in psychosis and those induced by $\triangle 9$-THC, results of studies investigating the opposing effects of CBD and $\triangle 9$-THC in healthy individuals are also highly informative.

In healthy individuals, the neural effects of CBD compared to those of $\triangle 9$-THC are relatively consistent, generally showing a direct and opposite effect on brain activation and connectivity during cognitive tasks, including salience processing, emotional processing, learning, and short-term memory. ${ }^{34,37,55,99,100}$ The results of both human and animal studies exploring the behavioural effects of CBD in comparison to $\triangle 9$-THC on these same cognitive processes that are also strongly affected in schizophrenia, specifically learning and short-term memory, have thus far been less consistent. ${ }^{54,55,101,102}$ This variability may be related to a number of factors, such as the heterogeneity of study designs (including varying CBD dosage) and modest sample sizes, together with limited overall research on the topic. In particular, differences in cognitive activations tasks employed in previous studies may have contributed to inconsistency in results. Not only have previous studies employed cognitive tasks that engage different cognitive domains, they also commonly vary in degree of difficulty, ${ }^{20}$ hindering crossstudy comparability.

\section{Future research directions}

As outlined above, despite the importance of such investigations for understanding the neurobiological underpinnings of psychosis, there is a clear lack of studies that have investigated the relationship between dynamic perturbation of the eCB system and functional brain abnormalities, or indeed FC between the DMN, SN and CEN in patients with psychosis. We posit that the optimal approach to address this gap would be for studies to investigate the effects of acute and/or short-term perturbation of the eCB system in patients with psychosis. Exploration of the role of the eCB system in the neurobiology of psychosis is most ideal in the early stages of psychosis, as such studies will be able to overcome issues relating to the longer term effects of illness course and antipsychotic treatment on aspects of cognition. ${ }^{2,103}$.

Indeed, previous research has also shown functional dysconnectivity to become increasingly widespread from the early to the latter stages of schizophrenia. ${ }^{104}$. Changes in FC have also been observed after relatively short-term antipsychotic use (12 weeks). ${ }^{105}$ Utilising a paradigm that focuses both on resting state abnormalities as well as the cognitive domains that are notably impaired in early psychosis, such as verbal memory, will be particularly useful in informing a comprehensive understanding of the role of the $\mathrm{eCB}$ system in large scale network dysconnectivity in psychosis.

\section{Conclusions}

Overall, such an approach may help connect multiple theoretical strands in schizophrenia research and rationally integrate a role for the eCB system into the relatively well-established dysconnectivity theory, focusing on the dysconnectivity of large-scale networks in psychosis. This may help formulate a comprehensive framework for the neurocognitive abnormalities underlying psychosis.

\section{Acknowledgments}

This work was supported by grants to Dr Sagnik Bhattacharyya from the Medical Research Council (MRC), UK (MR/J012149/1; MC_PC_14105 v.2). Sagnik Bhattacharyya has also received support from the National Institute for Health Research (NIHR) 
(NIHR Clinician Scientist Award; NIHR CS-11-001) and from the NIHR Mental Health Biomedical Research Centre at South London and Maudsley National Health Service (NHS) Foundation Trust and King's College London. Aisling O'Neill was supported by the NIHR Collaboration for Leadership in Applied Health Research and Care South London at King's College Hospital NHS Foundation Trust. The views expressed are those of the author(s) and not necessarily those of the NHS, the NIHR or the Department of Health.

\section{Conflict of interest}

The authors have no conflict of interests related to this publication.

\section{Author contributions}

Both of the authors contributed in a substantial way to the study, and approved the manuscript content. Both authors were involved in the design, analysis and interpretation of findings. O'Neill A wrote the first draft of the manuscript, and both authors contributed to its critical revision and gave final approval of the version for publication.

\section{References}

[1] World Health Organization. The world health report 2001: mental health: new understanding, new hope. Geneva: World Health Organization; 2001. Available from: EBSCOhost http://search.ebscohost.com/login.aspx?direct=truescope=sitedb=nlebkdb=nlabk $\mathrm{AN}=114062$.

[2] Corigliano V, De Carolis A, Trovini G, Dehning J, Di Pietro S, Curto $M$, et al. Neurocognition in schizophrenia: from prodrome to multi-episode illness. Psychiatry Res 2014;220(1-2):129-134. doi:10.1016/j.psychres.2014.07.067.

[3] Alonso-Solís A, Corripio I, de Castro-Manglano P, Duran-Sindreu S, Garcia-Garcia M, Proal E, et al. Altered default network resting state functional connectivity in patients with a first episode of psychosis. Schizophr Res 2012;139(1-3):13-18. doi:10.1016/j. schres.2012.05.005.

[4] van Os J, Kapur S. Schizophrenia. Lancet 2009;374(9690):635-645. doi:10.1016/S0140-6736(09)60995-8.

[5] Frangou S, Byrne P. How to manage the first episode of schizophrenia. BMJ 2000;321(7260):522-523. doi:10.1136/bmj.321.7260.522.

[6] Modinos G, lyegbe C, Prata D, Rivera M, Kempton MJ, Valmaggia $\mathrm{LR}$, et al. Molecular genetic gene-environment studies using candidate genes in schizophrenia: a systematic review. Schizophr Res 2013;150(2-3):356-365. doi:10.1016/j.schres.2013.09.010.

[7] Gurung R, Prata DP. What is the impact of genome-wide supported risk variants for schizophrenia and bipolar disorder on brain structure and function? A systematic review. Psychol Med 2015;45(12):2461-2480. doi:10.1017/S0033291715000537.

[8] Pelayo-Terán JM, Suárez-Pinilla P, Chadi N, Crespo-Facorro B. Geneenvironment interactions underlying the effect of cannabis in first episode psychosis. Curr Pharm Des 2012;18(32):5024-5035. doi:10.2174/138161212802884609.

[9] United Nations. World drug report 2016. United Nations Pubns, 2016.

[10] The Schizophrenia Commission. The abandoned illness: a report from the Schizophrenia Commission. London: The Schizophrenia Commission, 2012.

[11] Patel R, Wilson R, Jackson R, Ball M, Shetty $H$, Broadbent $M$, et al. Association of cannabis use with hospital admission and antipsychotic treatment failure in first episode psychosis: an observational study. BMJ Open 2016;6(3):e009888. doi:10.1136/bmjo- pen-2015-009888.

[12] Schoeler T, Petros N, Di Forti M, Klamerus E, Foglia E, Ajnakina O, et al. Effects of continuation, frequency, and type of cannabis use on relapse in the first 2 years after onset of psychosis: an observational study. Lancet Psychiatry 2016;3(10):947-953. doi:10.1016/ S2215-0366(16)30188-2.

[13] Schoeler T, Petros N, Di Forti M, Pingault JB, Klamerus E, Foglia $\mathrm{E}$, et al. Association Between Continued Cannabis Use and Risk of Relapse in First-Episode Psychosis: A Quasi-Experimental Investigation Within an Observational Study. JAMA Psychiatry 2016;73(11):1173-1179. doi:10.1001/jamapsychiatry.2016.2427.

[14] Marconi A, Di Forti M, Lewis CM, Murray RM, Vassos E. Meta-analysis of the Association Between the Level of Cannabis Use and Risk of Psychosis. Schizophr Bull 2016;42(5):1262-1269. doi:10.1093/ schbul/sbw003.

[15] Schoeler T, Monk A, Sami MB, Klamerus E, Foglia E, Brown R, et al. Continued versus discontinued cannabis use in patients with psychosis: a systematic review and meta-analysis. Lancet Psychiatry 2016;3(3):215-225. doi:10.1016/S2215-0366(15)00363-6.

[16] Potter DJ, Clark P, Brown MB. Potency of delta 9-THC and other cannabinoids in cannabis in England in 2005: implications for psychoactivity and pharmacology. J Forensic Sci 2008;53(1):90-94 doi:10.1111/j.1556-4029.2007.00603.x.

[17] Di Forti M, Morgan C, Dazzan P, Pariante C, Mondelli V, Marques TR, et al. High-potency cannabis and the risk of psychosis. Br J Psychiatry 2009;195(6):488-491. doi:10.1192/bjp.bp.109.064220.

[18] Hardwick S, King LA. Home Office cannabis potency study 2008. United Kingdom: Home Office Scientific Development Branch, 2008.

[19] Di Forti M, Marconi A, Carra E, Fraietta S, Trotta A, Bonomo M, et al. Proportion of patients in south London with first-episode psychosis attributable to use of high potency cannabis: a case-control study. Lancet Psychiatry 2015;2(3):233-238. doi:10.1016/S22150366(14)00117-5.

[20] Bossong MG, Jansma JM, Bhattacharyya S, Ramsey NF. Role of the endocannabinoid system in brain functions relevant for schizophrenia: an overview of human challenge studies with cannabis or $\Delta$ 9-tetrahydrocannabinol (THC). Prog Neuropsychopharmacol Biol Psychiatry 2014;52:53-69. doi:10.1016/j.pnpbp.2013.11.017.

[21] Pertwee RG. Ligands that target cannabinoid receptors in the brain: from THC to anandamide and beyond. Addict Biol 2008;13(2):147159. doi:10.1111/j.1369-1600.2008.00108.x.

[22] Pertwee RG. Targeting the endocannabinoid system with cannabinoid receptor agonists: pharmacological strategies and therapeutic possibilities. Philos Trans R Soc Lond B Biol Sci 2012;367(1607): 3353-3363. doi:10.1098/rstb.2011.0381.

[23] Mackie K. Distribution of cannabinoid receptors in the central and peripheral nervous system. Handb Exp Pharmacol 2005;168:299325. doi:10.1007/3-540-26573-2_10.

[24] Egerton A, Allison C, Brett RR, Pratt JA. Cannabinoids and prefrontal cortical function: insights from preclinical studies. Neurosci Biobehav Rev 2006;30(5):680-695. doi:10.1016/j.neubiorev.2005.12.002.

[25] Eggan SM, Lewis DA. Immunocytochemical distribution of the cannabinoid CB1 receptor in the primate neocortex: a regional and laminar analysis. Cereb Cortex 2007;17(1):175-191. doi:10.1093/ cercor/bhj136.

[26] Mesholam-Gately RI, Giuliano AJ, Goff KP, Faraone SV, Seidman LJ. Neurocognition in first-episode schizophrenia: a meta-analytic review. Neuropsychology 2009;23(3):315-336. doi:10.1037/ a0014708.

[27] García-Gutiérrez MS, García-Bueno B, Zoppi S, Leza JC, Manzanares J. Chronic blockade of cannabinoid $C B 2$ receptors induces anxiolytic-like actions associated with alterations in GABA(A) receptors. Br J Pharmacol 2012;165(4):951-964. doi:10.1111/j.14765381.2011.01625.x.

[28] Van Sickle MD, Duncan M, Kingsley PJ, Mouihate A, Urbani P, Mackie $\mathrm{K}$, et al. Identification and functional characterization of brainstem cannabinoid CB2 receptors. Science 2005;310(5746):329332. doi:10.1126/science. 1115740

[29] Ortega-Alvaro A, Aracil-Fernández A, García-Gutiérrez MS, Navar- 
rete F, Manzanares J. Deletion of CB2 cannabinoid receptor induces schizophrenia-related behaviors in mice. Neuropsychopharmacology 2011;36(7):1489-1504. doi:10.1038/npp.2011.34.

[30] Ishiguro H, Iwasaki S, Teasenfitz L, Higuchi S, Horiuchi Y, Saito T, et al. Involvement of cannabinoid CB2 receptor in alcohol preference in mice and alcoholism in humans. Pharmacogenomics J 2007;7(6):380-385. doi:10.1038/sj.tpj.6500431.

[31] Navarrete F, Pérez-Ortiz JM, Manzanares J. Cannabinoid $\mathrm{CB}_{2}$ receptor-mediated regulation of impulsive-like behaviour in DBA/2 mice. Br J Pharmacol 2012;165(1):260-273. doi:10.1111/j.14765381.2011.01542.x.

[32] Kim J, Li Y. Chronic activation of CB2 cannabinoid receptors in the hippocampus increases excitatory synaptic transmission. J Physiol 2015;593(4):871-886. doi:10.1113/jphysiol.2014.286633.

[33] D'Souza DC, Perry E, MacDougall L, Ammerman Y, Cooper T, Wu YT, et al. The psychotomimetic effects of intravenous delta-9-tetrahydrocannabinol in healthy individuals: implications for psychosis. Neuropsychopharmacology 2004;29(8):1558-1572. doi:10.1038/ sj.npp.1300496.

[34] Bhattacharyya S, Crippa JA, Allen P, Martin-Santos R, Borgwardt S, Fusar-Poli $P$, et al. Induction of psychosis by $\Delta 9$-tetrahydrocannabinol reflects modulation of prefrontal and striatal function during attentional salience processing. Arch Gen Psychiatry 2012; 69(1):27-36. doi:10.1001/archgenpsychiatry.2011.161.

[35] Bossong MG, Jansma JM, van Hell HH, Jager G, Oudman E, Saliasi E, et al. Effects of 89 -tetrahydrocannabinol on human working memory function. Biol Psychiatry 2012;71(8):693-699. doi:10.1016/j. biopsych.2012.01.008.

[36] Bhattacharyya S, Atakan Z, Martin-Santos R, Crippa JA, Kambeitz J, Malhi S, et al. Impairment of inhibitory control processing related to acute psychotomimetic effects of cannabis. Eur Neuropsychopharmacol 2015;25(1):26-37. doi:10.1016/j.euroneuro.2014.11.018.

[37] Bhattacharyya S, Falkenberg I, Martin-Santos R, Atakan Z, Crippa JA, Giampietro V, et al. Cannabinoid modulation of functional connectivity within regions processing attentional salience. Neuropsychopharmacology 2015;40(6):1343-1352. doi:10.1038/ npp.2014.258.

[38] Bhattacharyya S, Atakan Z, Martin-Santos R, Crippa JA, McGuire PK. Neural mechanisms for the cannabinoid modulation of cognition and affect in man: a critical review of neuroimaging studies. Curr Pharm Des 2012;18(32):5045-5054. doi:10.2174/138161212802884636.

[39] Bossong MG, Jager G, Bhattacharyya S, Allen P. Acute and nonacute effects of cannabis on human memory function: a critical review of neuroimaging studies. Curr Pharm Des 2014;20(13):21142125. doi:10.2174/13816128113199990436.

[40] Appiah-Kusi E, Leyden E, Parmar S, Mondelli V, McGuire P, Bhattacharyya S. Abnormalities in neuroendocrine stress response in psychosis: the role of endocannabinoids. Psychol Med 2016;46(1):27-45. doi:10.1017/S0033291715001786.

[41] Fakhoury M. Could cannabidiol be used as an alternative to antipsychotics? J Psychiatr Res 2016;80:14-21. doi:10.1016/j.jpsychires.2016.05.013.

[42] Rogers RD. The roles of dopamine and serotonin in decision making: evidence from pharmacological experiments in humans. Neuropsychopharmacology 2011;36(1):114-132. doi:10.1038/npp.2010. 165.

[43] Chow JJ, Nickell JR, Darna M, Beckmann JS. Toward isolating the role of dopamine in the acquisition of incentive salience attribution. Neuropharmacology 2016;109:320-331. doi:10.1016/j.neuropharm.2016.06.028.

[44] Simpson EH, Kellendonk C, Kandel E. A possible role for the striatum in the pathogenesis of the cognitive symptoms of schizophrenia. Neuron 2010;65(5):585-596. doi:10.1016/j.neuron.2010.02.014.

[45] Howes OD, Kambeitz J, Kim E, Stahl D, Slifstein M, Abi-Dargham A, et al. The nature of dopamine dysfunction in schizophrenia and what this means for treatment. Arch Gen Psychiatry 2012;69(8):776786. doi:10.1001/archgenpsychiatry.2012.169.

[46] Tzavara ET, Li DL, Moutsimilli L, Bisogno T, Di Marzo V, Phebus LA, et al. Endocannabinoids activate transient receptor potential vanilloid 1 receptors to reduce hyperdopaminergia-related hyperactivity: therapeutic implications. Biol Psychiatry 2006;59(6):508-515. doi:10.1016/j.biopsych.2005.08.019.

[47] Solinas M, Justinova Z, Goldberg SR, Tanda G. Anandamide administration alone and after inhibition of fatty acid amide hydrolase (FAAH) increases dopamine levels in the nucleus accumbens shell in rats. J Neurochem 2006;98(2):408-419. doi:10.1111/j.14714159.2006.03880.x.

[48] Sami MB, Rabiner EA, Bhattacharyya S. Does cannabis affect dopaminergic signaling in the human brain? A systematic review of evidence to date. Eur Neuropsychopharmacol 2015;25(8):1201-1224. doi:10.1016/j.euroneuro.2015.03.011.

[49] Dalton VS, Long LE, Weickert CS, Zavitsanou K. Paranoid schizophrenia is characterized by increased CB1 receptor binding in the dorsolateral prefrontal cortex. Neuropsychopharmacology 2011;36(8):1620-1630. doi:10.1038/npp.2011.43.

[50] Muguruza C, Lehtonen M, Aaltonen N, Morentin B, Meana JJ, Callado LF. Quantification of endocannabinoids in postmortem brain of schizophrenic subjects. Schizophr Res 2013;148(1-3):145-150. doi:10.1016/j.schres.2013.06.013.

[51] Di Marzo V, Berrendero F, Bisogno T, González S, Cavaliere P, Romero $\mathrm{J}$, et al. Enhancement of anandamide formation in the limbic forebrain and reduction of endocannabinoid contents in the striatum of delta9-tetrahydrocannabinol-tolerant rats. J Neurochem 2000;74(4):1627-1635. doi:10.1046/j.1471-4159.2000.0741627.x

[52] Leweke FM, Giuffrida A, Koethe D, Schreiber D, Nolden BM, Kranaster $L$, et al. Anandamide levels in cerebrospinal fluid of first-episode schizophrenic patients: impact of cannabis use. Schizophr Res 2007;94(1-3):29-36. doi:10.1016/j.schres.2007.04.025.

[53] Leweke FM, Piomelli D, Pahlisch F, Muhl D, Gerth CW, Hoyer C, et al. Cannabidiol enhances anandamide signaling and alleviates psychotic symptoms of schizophrenia. Transl Psychiatry 2012;2:e94. doi:10.1038/tp.2012.15.

[54] Englund A, Morrison PD, Nottage J, Hague D, Kane F, Bonaccorso $\mathrm{S}$, et al. Cannabidiol inhibits THC-elicited paranoid symptoms and hippocampal-dependent memory impairment. J Psychopharmacol 2013;27(1):19-27. doi:10.1177/0269881112460109.

[55] Bhattacharyya S, Morrison PD, Fusar-Poli P, Martin-Santos R, Borgwardt S, Winton-Brown T, et al. Opposite effects of delta-9-tetrahydrocannabinol and cannabidiol on human brain function and psychopathology. Neuropsychopharmacology 2010;35(3):764-774. doi:10.1038/npp.2009.184.

[56] Mechoulam R, Peters M, Murillo-Rodriguez E, Hanus LO. Cannabidiol-recent advances. Chem Biodivers 2007;4(8):1678-1692. doi:10.1002/cbdv.200790147.

[57] Thomas A, Baillie GL, Phillips AM, Razdan RK, Ross RA, Pertwee RG. Cannabidiol displays unexpectedly high potency as an antagonist of CB1 and CB2 receptor agonists in vitro. Br J Pharmacol 2007;150(5):613-623. doi:10.1038/sj.bjp.0707133.

[58] Bisogno T, Hanus L, De Petrocellis L, Tchilibon S, Ponde DE, Brandi I, et al. Molecular targets for cannabidiol and its synthetic analogues: effect on vanilloid VR1 receptors and on the cellular uptake and enzymatic hydrolysis of anandamide. $\mathrm{Br} \mathrm{J}$ Pharmacol 2001;134(4):845-852. doi:10.1038/sj.bjp.0704327.

[59] Leweke FM, Mueller JK, Lange B, Rohleder C. Therapeutic Potential of Cannabinoids in Psychosis. Biol Psychiatry 2016;79(7):604-612. doi:10.1016/j.biopsych.2015.11.018.

[60] Campos AC, Fogaça MV, Sonego AB, Guimarães FS. Cannabidiol, neuroprotection and neuropsychiatric disorders. Pharmacol Res 2016;112:119-127. doi:10.1016/j.phrs.2016.01.033.

[61] Bergamaschi MM, Queiroz RH, Zuardi AW, Crippa JA. Safety and side effects of cannabidiol, a Cannabis sativa constituent. Curr Drug Saf 2011;6(4):237-249. doi:10.2174/157488611798280924.

[62] Brown GG, Thompson WK. Functional brain imaging in schizophrenia: selected results and methods. Curr Top Behav Neurosci 2010;4:181-214. doi:10.1007/7854_2010_54.

[63] Gong Q, Hu X, Pettersson-Yeo W, Xu X, Lui S, Crossley N, et al. Network-Level Dysconnectivity in Drug-Naïve First-Episode Psychosis: Dissociating Transdiagnostic and Diagnosis-Specific Alterations. Neuropsychopharmacology 2017;42(4):933-940. doi:10.1038/ npp.2016.247.

[64] Menon V. Large-scale brain networks and psychopathology: a unifying triple network model. Trends Cogn Sci 2011;15(10):483-506. 
doi:10.1016/j.tics.2011.08.003.

[65] Friston KJ. Dysfunctional connectivity in schizophrenia. World Psychiatry 2002;1(2):66-71.

[66] Bullmore ET, Frangou S, Murray RM. The dysplastic net hypothesis: an integration of developmental and dysconnectivity theories of schizophrenia. Schizophr Res 1997;28(2-3):143-156. doi:10.1016/ S0920-9964(97)00114-X.

[67] Stephan KE, Friston KJ, Frith CD. Dysconnection in schizophrenia: from abnormal synaptic plasticity to failures of self-monitoring. Schizophr Bull 2009;35(3):509-527. doi:10.1093/schbul/sbn176.

[68] Friston KJ. Functional and effective connectivity: a review. Brain Connect 2011;1(1):13-36. doi:10.1089/brain.2011.0008.

[69] Yoon YB, Yun JY, Jung WH, Cho KI, Kim SN, Lee TY, et al. Altered Fronto-Temporal Functional Connectivity in Individuals at UltraHigh-Risk of Developing Psychosis. PLoS One 2015;10(8):e0135347. doi:10.1371/journal.pone.0135347.

[70] Zhang Y, Zheng J, Fan X, Guo X, Guo W, Yang G, et al. Dysfunctional resting-state connectivities of brain regions with structural deficits in drug-naive first-episode schizophrenia adolescents. Schizophr Res 2015;168(1-2):353-359. doi:10.1016/j.schres.2015.07.031.

[71] Buckner RL, Andrews-Hanna JR, Schacter DL. The brain's default network: anatomy, function, and relevance to disease. Ann $\mathrm{N} \mathrm{Y}$ Acad Sci 2008;1124:1-38. doi:10.1196/annals.1440.011.

[72] Andrews-Hanna JR, Smallwood J, Spreng RN. The default network and self-generated thought: component processes, dynamic control, and clinical relevance. Ann N Y Acad Sci 2014;1316:29-52. doi:10.1111/nyas.12360.

[73] Sheffield JM, Barch DM. Cognition and resting-state functional connectivity in schizophrenia. Neurosci Biobehav Rev 2016;61:108120. doi:10.1016/j.neubiorev.2015.12.007.

[74] Littow H, Huossa V, Karjalainen S, Jääskeläinen E, Haapea M, Miettunen J, et al. Aberrant Functional Connectivity in the Default Mode and Central Executive Networks in Subjects with Schizophrenia - A Whole-Brain Resting-State ICA Study. Front Psychiatry 2015;6:26. doi:10.3389/fpsyt.2015.00026.

[75] Menon V. Salience Network. In: Brain Mapping: An Encyclopedic Reference [Internet]. Academic Press: Elsevier; 2015:597-611.

[76] Sridharan D, Levitin DJ, Menon V. A critical role for the right frontoinsular cortex in switching between central-executive and defaultmode networks. Proc Natl Acad Sci U S A 2008;105(34):1256912574. doi:10.1073/pnas.0800005105.

[77] Manoliu A, RiedI V, Zherdin A, Mühlau M, Schwerthöffer D, Scherr $M$, et al. Aberrant dependence of default mode/central executive network interactions on anterior insular salience network activity in schizophrenia. Schizophr Bull 2014;40(2):428-437. doi:10.1093/ schbul/sbt037.

[78] Kapur S. Psychosis as a state of aberrant salience: a framework linking biology, phenomenology, and pharmacology in schizophrenia. Am J Psychiatry 2003;160(1):13-23. doi:10.1176/appi.ajp.160. 1.13.

[79] Wylie KP, Tregellas JR. The role of the insula in schizophrenia. Schizophr Res 2010;123(2-3):93-104. doi:10.1016/j.schres.2010.08.027.

[80] Whitfield-Gabrieli S, Thermenos HW, Milanovic S, Tsuang MT, Faraone SV, McCarley RW, et al. Hyperactivity and hyperconnectivity of the default network in schizophrenia and in first-degree relatives of persons with schizophrenia. Proc Natl Acad Sci U S A 2009;106(4):1279-1284. doi:10.1073/pnas.0809141106.

[81] Moran LV, Tagamets MA, Sampath H, O'Donnell A, Stein EA, Kochunov $P$, et al. Disruption of anterior insula modulation of large-scale brain networks in schizophrenia. Biol Psychiatry 2013;74(6):467474. doi:10.1016/j.biopsych.2013.02.029.

[82] Nekovarova T, Fajnerova I, Horacek J, Spaniel F. Bridging disparate symptoms of schizophrenia: a triple network dysfunction theory. Front Behav Neurosci 2014;8:171. doi:10.3389/fnbeh.2014.00171.

[83] Beaulieu JM, Gainetdinov RR. The physiology, signaling, and pharmacology of dopamine receptors. Pharmacol Rev 2011;63(1):182217. doi:10.1124/pr.110.002642.

[84] Gorka SM, Phan KL, Lyons M, Mori S, Angstadt M, Rabinak CA. Cannabinoid Modulation of Frontolimbic Activation and Connectivity During Volitional Regulation of Negative Affect. Neuropsychopharmacology 2016;41(7):1888-1896. doi:10.1038/npp.2015.359.
[85] Wijayendran SB, O'Neill A, Bhattacharyya S. The effects of cannabis use on salience attribution: a systematic review. Acta Neuropsychiatr 2016:1-15. doi:10.1017/neu.2016.58.

[86] Kraguljac NV, Srivastava A, Lahti AC. Memory deficits in schizophrenia: a selective review of functional magnetic resonance imaging (FMRI) studies. Behav Sci (Basel) 2013;3(3):330-347. doi:10.3390/ bs3030330.

[87] Schoeler T, Kambeitz J, Behlke I, Murray R, Bhattacharyya S. The effects of cannabis on memory function in users with and without a psychotic disorder: findings from a combined meta-analysis. Psychol Med 2016;46(1):177-188. doi:10.1017/S0033291715001646.

[88] Schoeler T, Bhattacharyya S. The effect of cannabis use on memory function: an update. Subst Abuse Rehabil 2013;4:11-27. doi:10.2147/SAR.S25869.

[89] Broyd SJ, van Hell HH, Beale C, Yücel M, Solowij N. Acute and Chronic Effects of Cannabinoids on Human Cognition-A Systematic Review. Biol Psychiatry 2016;79(7):557-567. doi:10.1016/j. biopsych.2015.12.002.

[90] Mottaghy FM. Interfering with working memory in humans. Neuroscience 2006;139(1):85-90. doi:10.1016/j.neuroscience.2005.05. 037.

[91] Pirnia T, Woods RP, Hamilton LS, Lyden H, Joshi SH, Asarnow RF, et al. Hippocampal dysfunction during declarative memory encoding in schizophrenia and effects of genetic liability. Schizophr Res 2015;161(2-3):357-366. doi:10.1016/j.schres.2014.11.030.

[92] Ragland JD, Ranganath C, Harms MP, Barch DM, Gold JM, Layher E, et al. Functional and Neuroanatomic Specificity of Episodic Memory Dysfunction in Schizophrenia: A Functional Magnetic Resonance Imaging Study of the Relational and Item-Specific Encoding Task. JAMA Psychiatry 2015;72(9):909-916. doi:10.1001/jamapsychiatry.2015.0276.

[93] Meda SA, Stevens MC, Folley BS, Calhoun VD, Pearlson GD. Evidence for anomalous network connectivity during working memory encoding in schizophrenia: an ICA based analysis. PLoS One 2009;4(11):e7911. doi:10.1371/journal.pone.0007911.

[94] Hutcheson NL, Sreenivasan KR, Deshpande G, Reid MA, Hadley J, White DM, et al. Effective connectivity during episodic memory retrieval in schizophrenia participants before and after antipsychotic medication. Hum Brain Mapp 2015;36(4):1442-1457. doi:10.1002/ hbm. 22714.

[95] Haut KM, van Erp TG, Knowlton B, Bearden CE, Subotnik K, Ventura J, et al. Contributions of Feature Binding During Encoding and Functional Connectivity of the Medial Temporal Lobe Structures to Episodic Memory Deficits Across the Prodromal and First-Episode Phases of Schizophrenia. Clin Psychol Sci 2015;3(2):159-174. doi:10.1177/2167702614533949.

[96] Wolf DH, Gur RC, Valdez JN, Loughead J, Elliott MA, Gur RE, et al. Alterations of fronto-temporal connectivity during word encoding in schizophrenia. Psychiatry Res 2007;154(3):221-232. doi:10.1016/j. pscychresns.2006.11.008.

[97] Bossong MG, Jager G, van Hell HH, Zuurman L, Jansma JM, Mehta $M A$, et al. Effects of $\Delta 9$-tetrahydrocannabinol administration on human encoding and recall memory function: a pharmacological FMRI study. J Cogn Neurosci 2012;24(3):588-599. doi:10.1162/ jocn a 00156.

[98] Bhattacharyya S, Fusar-Poli P, Borgwardt S, Martin-Santos R, Nosarti C, O'Carroll C, et al. Modulation of mediotemporal and ventrostriatal function in humans by Delta9-tetrahydrocannabinol: a neural basis for the effects of Cannabis sativa on learning and psychosis. Arch Gen Psychiatry 2009;66(4):442-451. doi:10.1001/ archgenpsychiatry.2009.17.

[99] Batalla A, Crippa JA, Busatto GF, Guimaraes FS, Zuardi AW, Valverde $\mathrm{O}$, et al. Neuroimaging studies of acute effects of THC and CBD in humans and animals: a systematic review. Curr Pharm Des 2014;20(13):2168-2185. doi:10.2174/13816128113199990432.

[100] Winton-Brown TT, Allen P, Bhattacharyya S, Borgwardt SJ, FusarPoli P, Crippa JA, et al. Modulation of auditory and visual processing by delta-9-tetrahydrocannabinol and cannabidiol: an FMRI study. Neuropsychopharmacology 2011;36(7):1340-1348. doi:10.1038/ npp.2011.17.

[101] Fadda P, Robinson L, Fratta W, Pertwee RG, Riedel G. Differential 
J Explor Res Pharmacol

effects of THC- or CBD-rich cannabis extracts on working memory in rats. Neuropharmacology 2004;47(8):1170-1179. doi:10.1016/j. neuropharm.2004.08.009.

[102] Wright MJ Jr, Vandewater SA, Taffe MA. Cannabidiol attenuates deficits of visuospatial associative memory induced by $\Delta(9)$ tetrahydrocannabinol. Br J Pharmacol 2013;170(7):1365-1373. doi:10.1111/bph.12199.

[103] Husa AP, Rannikko I, Moilanen J, Haapea M, Murray GK, Barnett J, et al. Lifetime use of antipsychotic medication and its relation to change of verbal learning and memory in midlife schizophrenia - An
O'Neill A. et al: Endocannabinoid system and psychosis

observational 9-year follow-up study. Schizophr Res 2014;158(13):134-141. doi:10.1016/j.schres.2014.06.035.

[104] Li T, Wang Q, Zhang J, Rolls ET, Yang W, Palaniyappan L, et al. BrainWide Analysis of Functional Connectivity in First-Episode and Chronic Stages of Schizophrenia. Schizophr Bull 2017;43(2):436448. doi:10.1093/schbul/sbw099.

[105] Sarpal DK, Robinson DG, Lencz T, Argyelan M, Ikuta T, Karlsgodt K, et al. Antipsychotic treatment and functional connectivity of the striatum in first-episode schizophrenia. JAMA Psychiatry 2015;72(1):513. doi:10.1001/jamapsychiatry.2014.1734. 